\title{
A SOLUTION TO AN OPEN PROBLEM
}

\section{FOR WILKER-TYPE INEQUALITIES}

\section{Chen-ShIPING* AND GE-XINYU}

Abstract. This paper is to solve the open problem for Wilker-Type inequality: what are the best possible for the constants $c_{1}$ and $c_{2}$ such that the double inequality $c_{1} x^{3 a} \tan x<\left(\frac{\sin x}{x}\right)^{2 a}+$ $\left(\frac{\tan x}{x}\right)^{a}-2<c_{2} x^{3 a} \tan x$ holds?

Mathematics subject classification (2010): 26D05, 33B10.

Keywords and phrases: Wilker-type inequality, trigonometric function, open problem.

\section{REFERENCES}

[1] J. B. Wilker, Problem E3306, The American Mathematical Monthly 96, 1 (1989), 55.

[2] J. S. Sumner, A. A. Jagers, M. Vowe AND J. Anglesio, Inequalities involving trigonometric functions, The American Mathematical Monthly 98, 3 (1991), 264-267.

[3] Ling ZHU, Some New Wilker-Type Inequalities for Circular and Hyperbolic Functions, Abstract and Applied Analysis, 1 (2009), 9 pages, doi:10.1155/2009/485842.

[4] Edward Neuman, Inequalities Involving Generalized Trigonometric and Hyperbolic Functions, Journal of Mathematical Inequalities 8, 4 (2014), 19 pages, doi:10.7153/jmi-08-54.

[5] Ladislav MatejíčKa, Note On Two New Wilker-Type Inequalities, International Journal of Open Problems in Computer Science \& Mathematics 4, 1 (2011), 7 pages.

[6] Wei-Dong Jiang, QIU-Ming LuO And Feng QI, Refinements and Sharpening of some Huygens and Wilker Type Inequalities, Turkish Journal of Analysis and Number Theory 2, 4 (2014), 134-139, doi:10.12691/tjant-2-4-6.

[7] KuANg Jichang (Eds), Applied Inequalities, Shandong Science and Technology Press, 4th ed., Shandong, 2010. 